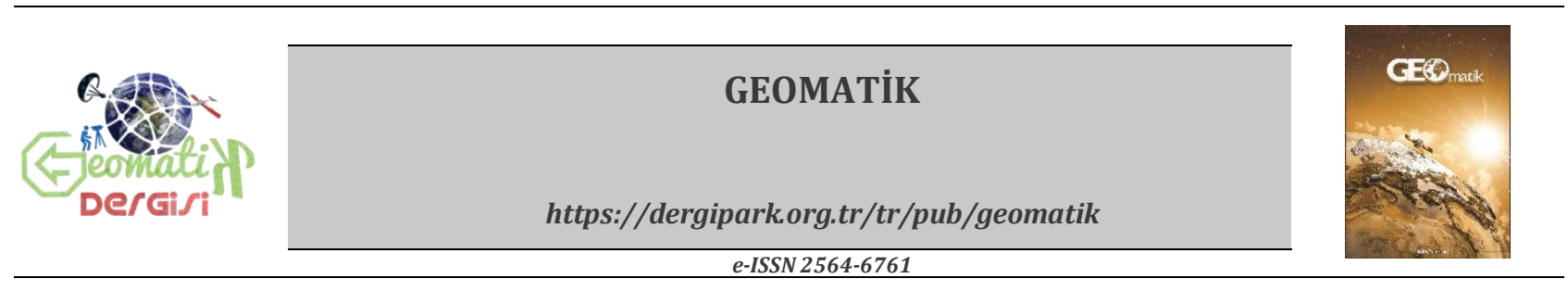

\title{
Fındık Bahçelerinin Sentinel-2 Verileri Kullanılarak Piksel Tabanlı Sınıflandırma Yöntemleriyle Belirlenmesi
}

\section{Ceyhun Apaydın', Saygın Abdikan ${ }^{*}$}

${ }^{1}$ Zonguldak Bülent Ecevit Üniversitesi, Geomatik Mühendisliği Bölümü, Zonguldak, Türkiye

\author{
Anahtar Kelimeler \\ Findlk \\ Rastgele Orman \\ Sentinel-2 \\ K-EYK \\ DVM
}

\begin{abstract}
ÖZ
Dünyada fındık üretiminin yaklaşık \%75'ini Türkiye sağlamaktadır. Bu nedenle fındık alanlarının doğru bir șekilde belirlenmesi, üretilecek fındık miktarının ve verimlilik çalışmaları için önemlidir. Bu çalışmada 02.07.2019 tarihli Sentinel-2 uydu görüntüsü kullanılarak findık bahçelerinin belirlenmesi amaçlanmıştır. Bu kapsamda çalışma alanı olarak Trabzon ili Beşikdüzü ilçesi, uygulama alanı olarak ilçe merkezi seçilmiştir. Uygulama alanına ait görüntü arazi tespit çalışması için piksel tabanlı görüntü sınıflandırma yöntemi kullanılmıştır. Fındık bahçelerinin belirlenmesi için üç farklı makine öğrenme algoritması rastgele orman (RO), K en yakın komşu (K-EYK) ve destek vektör makineleri (DVM) ele alınmıştır. Sınıflandırmalara ilişkin genel doğruluk değerleri RO, K-EYK ve DVM algoritmaları için sırasıyla 85,3870, 87,5398 ve 91,0948 olarak tespit edilmiștir.
\end{abstract}

\section{Determination of Hazelnut Gardens by Pixel Based Classification Methods Using Sentınel-2 Data}

\author{
Keywords \\ Hazelnut \\ Random Forest \\ Sentinel-2 \\ KNN \\ SVM
}

\begin{abstract}
Turkey provides approximately $75 \%$ of world hazelnut production. Therefore, accurate determination of hazelnut areas is important for the amount of hazelnut production and productivity studies. In this study, it was aimed to determine the hazelnut orchards using the Sentinel-2 satellite image dated 02.07.2019. In this context, Beşikdüzü District of Trabzon province was selected as the study area and district center as the application area. Pixel-based image classification method is used for land detection. Three different machine learning algorithms random forest (RF), K nearest neighbor (KNN) and support vector machines (SVM) were applied to identify hazelnut gardens. General accuracy values for classifications were determined as 85,3870, 87,5398 and 91,0948 for RF, KNN and SVM algorithms, respectively.
\end{abstract}




\section{GíRiş}

Türkiye, dünya fındık üretiminin yaklaşık \%75'ini, ihracatının ise \%70-75'ini gerçekleștirmektedir. Ülkemiz bulunduğu coğrafi koşullar ve sahip olduğu uygun ekolojik yapısı nedeniyle fındık yetiştiriciliğinin yapıldığı ülkeler arasında dünyanın en önemli üreticisi olma özelliğine sahiptir. Fındık bahçelerinin alanlarının tespit edilmesi, üretim kapasitesinin belirlenmesi, yapılacak ekonomik planlamalarda özellikle teşvik uygulamalarının değerlendirilmesi açısından önemlidir. Ülke ekonomisi için vazgeçilmez, ekonomik katma değeri bakımından oldukça yüksek bir tarım ürünü olan findık Doğu Karadeniz bölgesinin en önemli geçim kaynaklarındandır (Url1).

Tarım arazilerinin etkin ve sürdürülebilir bir şekilde izlemek ve kullanılmasını sağlamak, tarım politikalarına yön verebilmek amacıyla uzaktan algılama tekniği ile yapılan çalışmalar önemlidir. Özellikle son zamanlarda tarım, doğal bitki örtüsü, ormancılık vb. amaçlara uygun algilayıcılar ve uydular tasarlanmaktadır ve bu konudaki çalışmalar hızla gelişmeye devam etmektedir (Üstüner vd, 2014).

Akar ve ark. (2013), çalışmalarında çay ve fındık bahçelerinin belirlenmesi için 2012 yılına ait 8 bantlı multispektral (MS) ve pankromatik (PAN) WorldView-2 uydu görüntülerini kullanmışlardır. Bu örnek alanlara göre MS uydu görüntüsünden 7 farklı sınıf (orman, findık, çay, toprak, gölge, kentsel alan1 ve kentsel alan2) belirlenmiş ve RO sınıflandırma yöntemi kullanılmıştır. Öncelikli olarak ürünlerin sadece MS uydu görüntüsünden alınan spektral değerleri dikkate alınarak RO yöntemi uygulanmış ve genel sınıflandırma doğruluğu \%79,05 olarak elde edilmiştir. Spektral özellikler ile birlikte Eş Dizimlilik Matrisi kullanılarak elde edilen doku özellikleri de ele alındığında genel sınıflandırma doğruluğu \%84,08 olarak elde edilmiştir. Çalışmada doku özelliğinin sınıflandırma başarısına katkısı ortaya konulmuştur.

Ünal ve ark. (2010), Giresun ilinde findık alanlarının belirlenmesinde kontrollü sınıflandırma yöntemi kullanmışlardır. Çalışma kapsamında farklı çözünürlüklere sahip farklı uydu görüntüleri (SPOT, Quickbird-Pan ve IKONOS) ele alınmıştır. Kontrollü sinıflandırma yöntemi ile yapılan çalışmanın doğruluğu \%79,41 bulunmuştur. Sinıflandırma doğruluğu ayrıca farklı eğim grupları için de uygulanmış ve eğim aralığı $\% 10-\% 30$ olan bölgelerde yaklaşık \%85 olarak elde edilmiştir.

Reis ve ark. (2010) yüksek konumsal çözünürlüğe sahip Quickbird uydu görüntüsü kullanarak Trabzon'da seçilen bir bölgede fındık alanı belirlemiştir. Fındık bahçelerinin belirlenmesinde kendini örgütleyen eșlemler (Self Organizing Maps-SOM) yöntemi kullanılmıștır. Çalışmada spektral bilgiler ile birlikte PAN görüntünün Gabor öznitelik bilgisi de ele alınmıștır. SOM sınıflandırma yöntemi sadece spektral bantlara uygulandığında sınıflandırma doğruluğu \%82 ve Kappa değeri 0,73 olarak elde edilmiştir. Spektral bantlar ve Gabor öznitelik verisinin beraber ele alındığı veri seti sınıflandırıldı̆̆ında doğruluk oranı \%89 ve kappa katsayısı 0,84 elde edilmiştir. Çalıșma sonucunda Gabor öznitelik bilgisinin findığın diğer odunsu bitkilerden ayrılmasında etkili olduğu belirlenmiştir.

Sener ve ark. (2013), Sakarya șehrinde yapmıș oldukları çalışmada 2007 yılına ait Landsat uydu görüntüsü kullanmışlardır. 7 farklı sınıf belirlemiş ve sınıflandırma işlemini maksimum olabilirlik yöntemi ile gerçekleștirilmiştir. Çalışma sonucunda, fındık bahçelerinin ortalama sınıflandırma doğruluğu \% 86 ve kappa katsayısı 0,811 olarak bulunmuştur. Çalışma sonucunda fındık üretimine uygun olmayan yasa dışı üretim yapılan bahçeler tespit edilmiştir. Fındık üretim alanlarının planlı ve arz talep dengesinin kontrol altına alınmasının gerekliliğini göstermişlerdir.

Bu çalışmada önceki çalışmalardan farklı olarak çok yüksek çözünürlüklü uydu görüntüleri yerine ücretsiz olarak kullanıcılara sunulan $10 \mathrm{~m}$ konumsal çözünürlüğe sahip Sentinel-2 uydu görüntüsü kullanılmıştır. Bu çalışmanın amacı Sentinel-2 uydu görüntüsü kullanılarak piksel tabanlı sınıflandırma yöntemleri ile fındık bahçelerinin belirlenmesidir. Görüntülerin sınıflandırılmasında makine öğrenme algoritmalarından Rastgele Orman (RO), k-En Yakın Komşuluk (K-ENK) ve Destek Vektör Makineleri (DVM) yöntemi kullanılmış ve sonuçlar karşılaștırılmıștır.

\section{2. ÇALIŞMA ALANI VE VERI}

\section{1. Çalışma Alanı}

Çalışma kapsamında Trabzon ili Beşikdüzü ilçesi sınırları içerisinde kalan alan ele alınmıştır. Beşikdüzü ilçesi Trabzon'un $45 \mathrm{~km}$. batısında yer almaktadır. Kuzeyinde Karadeniz bulunan ilçenin, batısında Eynesil, doğusunda Vakfıkebir, güneyinde Şalpazarı ve Tonya ilçeleri bulunmaktadır. İlçenin 34 mahallesi vardır. Merkez nüfusu 21.870'dir. İlçe merkezi düz ve deniz seviyesi yüksekliğ̈indedir. İç kesimlere doğru eğimli ve engebeli bir araziye sahiptir. İlçenin yüzölçümü 121 km² 'dir (Şekil 1).

Tipik Karadeniz ikliminin görüldügüu ilçede, yaz ayları serin, kış aylarıda ılıktır. Her mevsim yağış görülmektedir. Ay bazında sıcaklık ortalamalarına bakıldığında en sıcak $22^{\circ} \mathrm{C}$ ve en soğuk $6^{\circ} \mathrm{C}$ dir. Nem oranı ise $\% 60$ ile $\% 70$ arasında değişmektedir. Akarsuları Kurbağalı dere ve Ağasar Deresi'dir. Önemli yükseltileri ise Yumru Tepeleri ve Beşikdağ'ıdır. Komşu ilçelerinin de yararlandığı Beşikdüzü Limanı doğal bir liman niteliğine sahiptir (URL-2). 

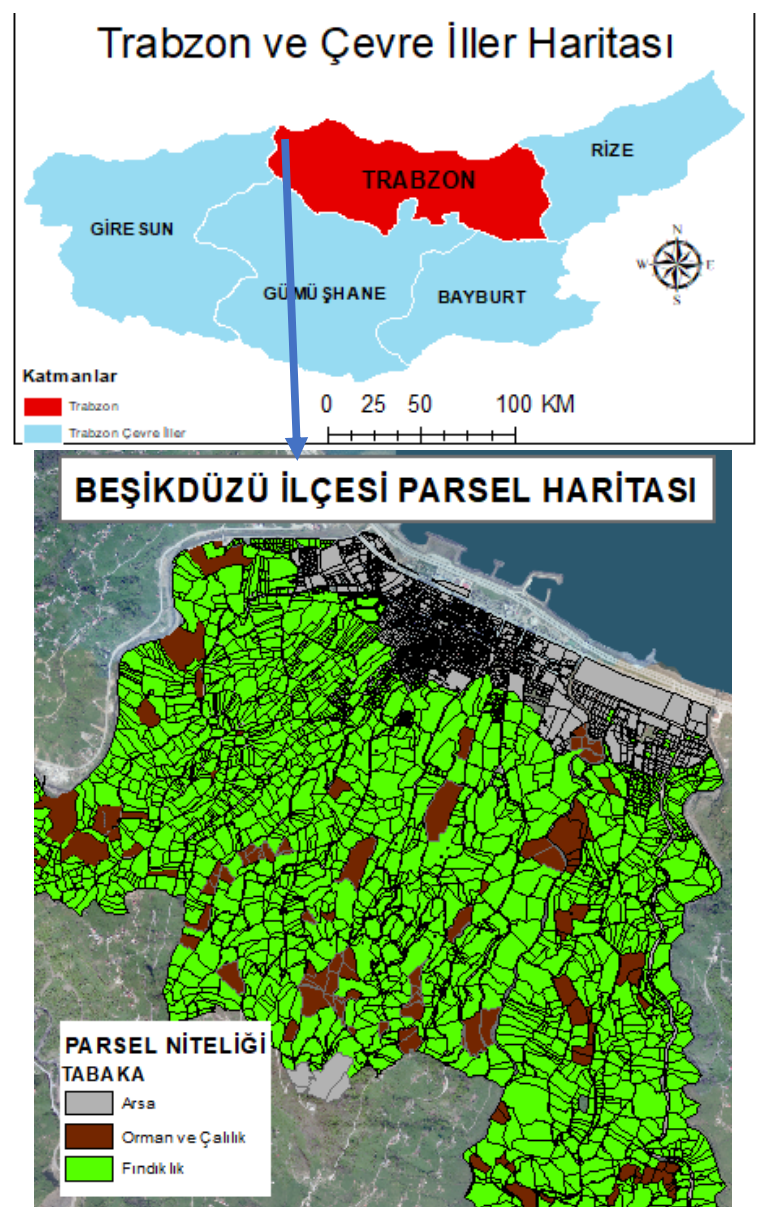

Şekil 1. Trabzon ve Çevre İller Haritası ve Beşikdüzü ilçesi Parsel Haritası Sınırları

\subsection{Kullanılan Veri}

Avrupa Uzay Ajansı (AUA) tarafindan geliştirilen Sentinel programı çerçevesinde her birinde 2 uydu bulunan 7 farklı uydu serisi yer almaktadır. Optik multispektral uydular olan Sentinel-2 uydu serisi Sentinel 2A ve 2B olmak üzere iki ikiz uydudan oluşur. Sentinel-2A uydusu Haziran 2015 ve Sentinel-2B uydusu Temmuz 2016 tarihinde fırlatılmıștır. İki uydu aynı yörüngede ve birbirine $180^{\circ}$ açıda hareket etmektedir. Sentinel-2 uyduları geniş alanları kaplamaları, yüksek konumsal ve spektral çözünürlüğe (13 spektral bant) sahip olmaları ile bitki örtüsünün ve yeryüzünün izlenmesi için önemli bir olanak sunmaktadır (Drusch ve ark., 2012). Yüksek konumsal çözünürlük, yeni spektral bantlar, geniş alanda görüntü alma ve ekvatorda 5 günde tekrar aynı yerden görüntü alabilme kabiliyeti Sentinel-2 uydusunu pek çok uygulamada oldukça kullanışlı hale getirmektedir (Malenovský ve ark. , 2012).

Kullanılan uydu görüntüleri AUA 'nın Copernicus Açık Erişim Merkezinden ücretsiz olarak https://scihub.copernicus.eu/dhus/\#/home

adresinden temin edilmiștir. Sentinel-2 görüntüsünde kullanılan spektral bantlar ve bantların özellikleri tablo 1 'de gösterilmektedir. Çalışma alanına ait uydu görüntüsü Șekil 2'de gösterilmektedir (Url-3).
Tablo 1. Sentinel-2 uydusunun spektral bantları

\begin{tabular}{|l|c|c|}
\hline Bantlar & $\begin{array}{c}\text { Orta Dalga Boyu } \\
(\mu \mathrm{m})\end{array}$ & $\begin{array}{c}\text { Cözzünürlük } \\
(\mathrm{m})\end{array}$ \\
\hline Bant 2 - Mavi & 0,490 & 10 \\
\hline Bant 3 - Yeșil & 0,560 & 10 \\
\hline Bant 4 Kırmıı & 0,665 & 10 \\
\hline $\begin{array}{l}\text { Bant 8 - Yakın } \\
\text { Kzzlötesi }\end{array}$ & 0,842 & 10 \\
\hline
\end{tabular}

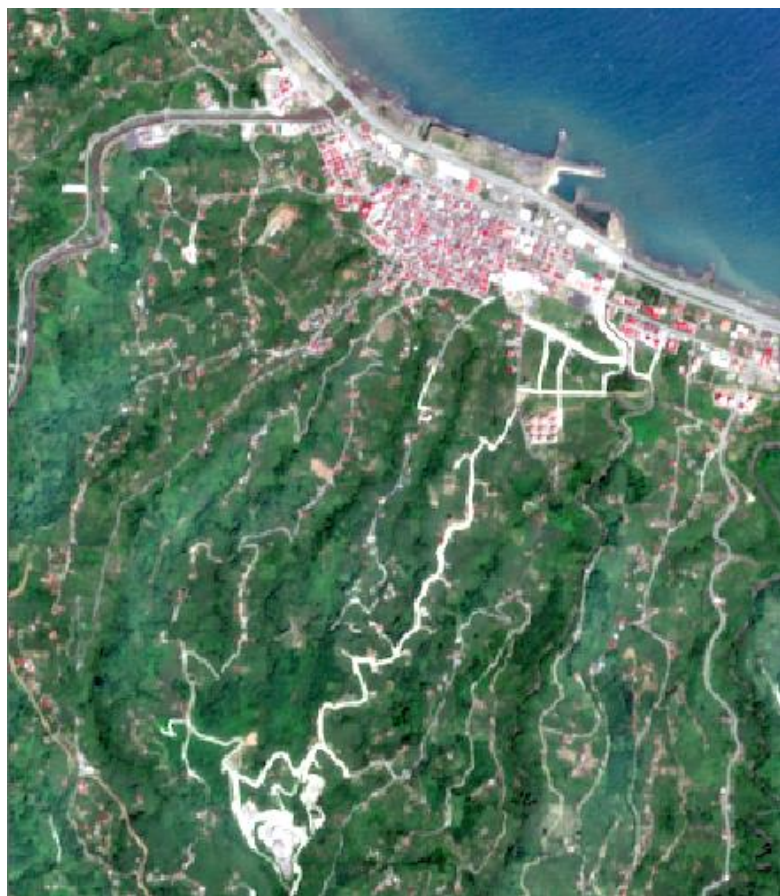

Şekil 2. Çalışma alanına ait 02.07.2019 tarihli Sentinel uydu görüntüsü (Kırmızı: Bant 3, Yeşil: Bant 2, Mavi Bant 1, Ölçek 1:30.000)

\section{YÖNTEM}

Görüntünün sınıflandırma aşamasından önce eğitim ve test verileri belirlenmiștir. Bu veriler Beşikdüzü Belediyesinden temin edilen veriler ve uydu görüntüsünün elde edildiği dönemde arazi çalışması yapılarak belirlenmiştir. Arazi çalışmalarıyla birlikte fındık bahçeleri parsel bazında tespit edilmiștir. Sınıflandırma ișlemlerinin yapılması için kullanıcı tarafından belirlenen yedi sınıf için eğitim verileri ve eğitim verilerinden bağımsız olarak test verileri seçilmiştir. Tablo 2'de sınıf sayıları ve sinıflar gösterilmektedir.

Eğitim örnek verilerini toplamak için, her arazi örtüsü sınıfı için 778 piksel olușturmak üzere ArcGIS 10.7 araç kutusundaki piksel oluşturma aracı kullanılmıştır ( Tablo 2 ).

Sınıflandırma işlemi tamamlandıktan sonra değerlendirme kısmında k-katlamalı çapraz doğrulama yöntemi kullanılmıștır. k-katlamalı çapraz doğrulama tekniğinde orijinal veri seti $\mathrm{k}$ sayıda parçaya bölünür. (k-1) sayıdaki parça sınıflandırıcı modeli eğitmek için kullanılırken, geriye kalan bir parça ise modelin doğruluğunu hesaplamak için kullanılır. Bu işlem $\mathrm{k}$ defa tekrar edilir ve her seferinde farklı parça eğitim ve test verisi olarak kullanılır. Elde edilen doğruluk 
değerlerinin ortalaması alınır. Modelin doğruluğu ise bu ortalama değere eşittir (Kohavi., 1995; Toosi vd., 2019, Üstüner vd., 2019). Bu çalışmada k değeri 5 olarak alınmıștır.

Sınıflandırma işlemlerinin yapılması için kullanıcı tarafından eğitim verileri seçilmiştir. Çalışma için bölgede yer alan deniz, bina, orman, fındıklık, asfalt yol, beton yol ve dere olmak üzere yedi sınıf belirlenmiştir. Doğruluk analizinde, 7 sınıf için seçilen eğitim verilerinden bağımsız olarak yine 7 sınıf için test verileri seçilmiştir. Toplam Piksel sayısı şu şekilde hesaplanmaktadır (Olofsson vd., (2014):

$$
N=\left(\sum i=1\left(W_{i}-S_{i}\right) / S_{o}\right) 2
$$

$\mathrm{W}_{\mathrm{i}}=$ sınıfın eşlenen alan oranı

$\mathrm{S}_{\mathrm{i}}=$ tabakanın standart sapması

$\mathrm{S}_{\mathrm{o}}=$ doğrulukta beklenen standart sapma

$\mathrm{c}=$ toplam sinıf sayısı

Toplam piksel sinıflarının sayıları hesaplandıktan sonra sınıfların piksel sayıları, eşit dağılımlı $\left(N_{i}=N / \mathrm{c}\right)$ ve ağırlıklı dağılımlı $\left(N_{i}=N * W_{i}\right)$ olarak belirlenebilir. Bu çalışmada her sınıf için yaklaşık piksel değerlerini bulmak için $N_{i}=\left(N / c+N * W_{i}\right) / 2$ formülü kullanılarak aşağıdaki tabloda eğitim ve test saylları eşit olmak üzere her sınıf için piksel sayıları hesaplanmıştır.

Tablo 2. Sinıflar için belirlenen eğitim ve test piksel sayısı

\begin{tabular}{|l|c|c|}
\hline Sinıflar & Eğitim Verisi & Test Verisi \\
\hline 1-Deniz & 177 & 177 \\
\hline 2-Bina & 75 & 75 \\
\hline 3-Orman & 113 & 113 \\
\hline 4-Fındıklık & 227 & 227 \\
\hline 5-Asfalt Yol & 60 & 60 \\
\hline 6-Beton Yol & 58 & 58 \\
\hline 7-Dere & 68 & 68 \\
\hline Toplam & 778 & 778 \\
\hline
\end{tabular}

Uydu görüntüleri üzerinden arazi örtüsünün tespiti için piksel ve nesne tabanlı olmak üzere iki ana sınıflandırma yöntemi yaklaşımı bulunmaktadır. Piksel tabanlı yaklaşımlar her bir piksel üzerinde çalışır ve ayrıca yalnızca spektral bilgilere dayanarak uzaktan algılanan verilerden bilgi alır (Gupta, 2014). Çalışmaya ait iş akış şeması Şekil 3'de gösterilmektedir.

\subsection{Sınıflandırma Yöntemleri}

Obje tabanlı ve klasik piksel tabanlı görüntü sınıflandırma yaklaşımlarına alternatif olarak uydu görüntülerinden güvenilir ve doğru bilgi üretmek için çeşitli öğrenme tabanlı algoritmalar geliştirilmektedir. Yaygın olarak kullanılan öğrenme tabanlı algoritmalar Rastgele Orman (RO), Yapay Sinir Ağları, Karar Ağacı, Hızlandırma, Torbalama,
Destek Vektör Makinesi (DVM) ve K-En Yakın Komşuluk' tur (Breiman 2001). Bu çalışma kapsamında, üç farklı makine öğrenme algoritması RO, K-EYK ve DVM kullanılmıștır.

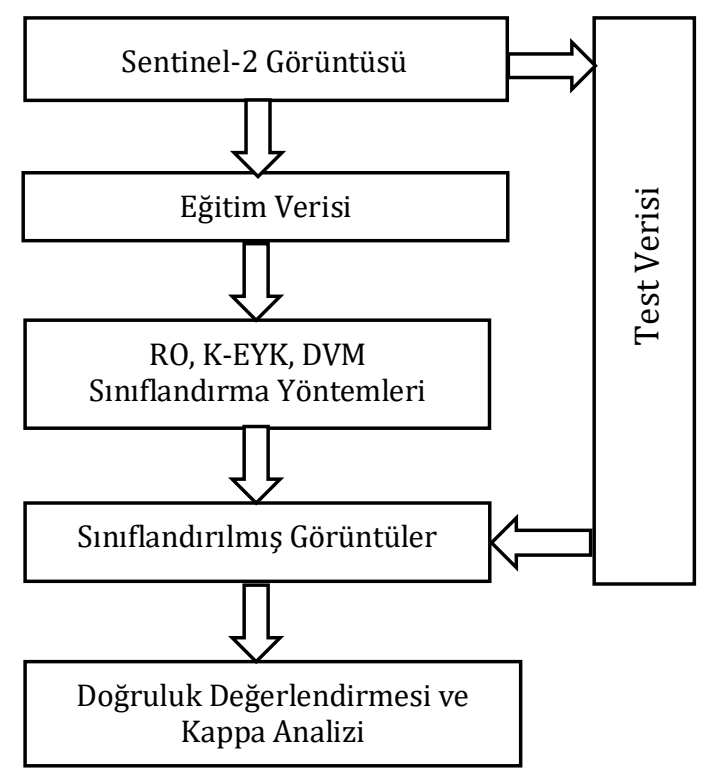

Şekil 3. Çalışmaya ait iş akış şeması

Arazi örtüsü ve kullanımı çalışmaları için bu sınıflandırma yöntemlerinin performansını kendi aralarında veya diğer sınıflandırma algoritmaları ile karşılaștırarak en iyi sınıflandırma algoritmasını bulmak için çeșitli çalıșmalar yapılmıștır. Adam ve ark. (2014) ile Ghosh ve Joshi (2014), DVM ve RO yöntemlerinin benzer sinıflandırma sonuçları gösterdiğini belirtmişlerdir. Khatami ve ark. (2016) DVM, K-EYK ve RO'nun genellikle diğer geleneksel kontrollü sınıflandırma yöntemlerinden daha iyi performans gösterdiğini belirtmişlerdir.

Rastgele orman, her ağacın bağımsız olarak ve tüm ağaçlar için aynı dağılımla örneklenmiş rastgele bir vektörün değerlerine bağlı olduğu bir ağaç topluluğu öğrenme algoritmasıdır. Böylece, rastgele bir orman birçok karar ağacından oluşur ve tek tek ağaçların verdiği kararların ortalamasını verir. Rasgele ormanların bir dizi pratik problem üzerinde yüksek performans sağladığı gösterilmiştir. Sinıflandırmada kullanıcı tarafından iki parametre belirlenir bunlar ağacın ne kadar geliștirileceğini tanımlayan ağaç sayısı ve ana düğümden kaç yeni düğümün ayrılabileceğini tanımlayan değişken sayısıdır. Bu çalışmada ağaç sayısı 10 ve değişken sayısı 2 olarak alınmıștır (Breiman 2001, Comert ve ark. 2019, Sevgen 2019).

K-En Yakın Komşu (K-EYK), parametrik olmayan bir yaklaşımdır (Duda ve ark. 1973). İstatistiksel uygulamalarda 1970'lerin bașında kullanılmaya başlanmıştır (Franco-Lopez ve ark. 2001). K-EYK'nın arkasındaki temel teori, kalibrasyon veri kümesinde, bilinmeyen örneklere en yakın olan bir grup k örneği bulmasıdır (örneğin, mesafe fonksiyonlarına bağlı olarak). Bu k örneklerinden, bilinmeyen örneklerin sınıfı (etiketi) 
yanıt değişkenlerinin ortalaması (yani en yakın komşunun sınıf özellikleri) hesaplanarak belirlenir (Akbulut, ve ark., 2017; Wei ve ark., 2017). Parametrik olmayan algoritma K-EYK, örnek tabanlı bir öğrenme yaklaşımını veya "tembel öğrenme" kullanır. $\mathrm{Bu}$ algoritma ile bir nesne, en yakın komşusunun $\mathrm{K}$ sınıf özelliklerine göre sınıflandırılır. Sonuç olarak, bu sınıflandırıcı için k, K-EYK'nin performansında önemli bir rol oynar, yani, K-EYK'nin önemli bir parametresidir (Qian, ve ark. 2015).

Destek Vektör Makinesi (DVM), sinıfları birbirinden en uygun şekilde ayırabilecek sınır hatlarının tanımlandığı istatistiksel bir kontrollü sınıflandırma yöntemidir. Burada temel amaç, destek vektörleri koşulunu gerçekleștiren iki doğrusal çizgi arasındaki marjin adı verilen uzaklığı maksimum değere çlkarmak ve ortadaki sınır karar yüzeyini bulmaktır. Yüzey genel olarak, en uygun hiper düzlem olarak adlandırılır. Destek vektörleri, hiper düzleme en yakın veri noktalarıdır (Url-4). Yöntem başta iki sınıflı doğrusal verilerin ayrıştırılması için tasarlanmıştır ancak daha sonra geliştirilerek çok sınıflı ve doğrusal olmayan veriler için de kullanılmıștır. Doğrusal olarak ayrılmadığı durumlarda, SVM'nin kernel versiyonları tanımlanır. Kernel yaklașımının temel hedefi, verileri ikili sinıflandırmanın tekrar doğrusal olarak elde edilebileceği daha yüksek boyutlu bir alana dönüştürmektir. En çok kullanılan kernel türleri lineer, sigmoid, polinom ve radyal tabanlı fonksiyon kernelleridir (Üstüner ve Balık Şanlı 2019, Abdikan ve ark. 2015). Bu çalışmada radyal tabanlı fonksiyon kerneli kullanılmıştır.

RO, K-EYK ve DVM algoritmaları ile sınıflandırmalar, açık kaynak kodlu QGIS kütüphanesinden faydalanarak gerçekleştirilmiştir. Daha sonra sınıflandırma doğrulukları incelenmiştir. Doğruluk değerlendirmesinin amacl, piksellerin doğru arazi örtüsü sınıflarına ne kadar etkili bir şekilde örneklendiğini nicel olarak değerlendirmektir (Rwanga ve Ndambuki 2017). Sınıflandırma performansının doğruluğunu değerlendirmek için, literatürde birçok metrik bulunmaktadır. Bunlardan ilki kappa istatistiğidir.

Kappa analizi doğruluk değerlendirmelerinde kullanılan çok değişkenli bir tekniktir. Kappa analizi formülü aşağıdaki gibidir.

$k=\frac{N \sum_{i=1}^{r} x_{i i}-\sum_{i=1}^{r}\left(x_{i+} \times x_{+i}\right)}{N^{2}-\sum_{i=1}^{r}\left(x_{i+} \times x_{+i}\right)}$,

Bu durumda,

$r=$ hata matrisindeki satır ve sütun sayısı,

$\mathrm{N}=$ toplam piksel sayısı,

$\mathrm{X}_{\mathrm{ii}}=$ satır i ve sütun i'de piksel,

$\mathrm{X} \mathrm{i}+=$ satır i'nin marjinal toplamı ve $\mathrm{X}+\mathrm{i}=$ sütun i'nin marjinal toplamı

1'e eşit bir Kappa katsayısı, mükemmel bir sonuç anlamına gelir iken burada sıfıra yakın bir değer, sinıflandırma sonucunun beklenenden daha iyi olmadığı anlamına gelir.
Ancak kappa analizi sınıflandırma sonuçlarının değerlendirilmesinde daha az yaygın hale gelmektedir, onun yerine daha kolay yorumlanan genel doğruluk tercih edilmektedir (Heydari ve ark. 2018). Sadece genel doğruluk metriğini kullanmanın dezavantajı ise sinıfların performansını göstermemesidir. Bu nedenle bu çalışmada kappa istatistiği ve genel doğruluk ile birlikte üretici ve kullanıcı doğruluk değerleri de sunulmuştur.

\section{BULGULAR VE TARTIŞMA}

RO, K-EYK ve DVM yöntemleriyle yapılan sınıflandırma sonuçları sırasıyla şekil $5 a, 5 b$ ve $5 c$ 'de, üretici doğruluğu (ÜD) ve kullanıcı doğruluğu (KD) sonuçları sirasıyla Tablo 3,4 ve 5'de gösterilmektedir. Doğruluk analizleri ve kappa değerleri ise Tablo 6'da verilmiștir.

RO ile elde edilen sonuç incelendiğinde; orman ve dere sınıfının ÜD değerlerinin diğer sınıflara göre düşük olduğu, KD incelendiğinde ise bina ve asfalt yol sınıflarının doğruluğunun düșük olduğu gözlenmiștir. Fındık sınıfının ise ÜD ve KD değerlerinin sirasıyla \%89 ve \%78 olarak belirlenmiștir.

K-EYK ile elde edilen sonuç incelendiğinde; orman ve beton yol sınıflarının ÜD değerlerinin diğer sınıflara göre daha düşük olduğu, kullanıcı doğruluğunda ise bina ve asfalt yol sinıflarının doğruluğunun düșük olduğu gözlenmiștir. Bunun sebebi olarak birbirine takın spektral değerlere sahip nesnelerin ayırt edilmesinde K-EYK yöntemin seçilen $\mathrm{k}$ değerine göre kararsız davranmasından kaynaklanmasıdır. Fındık sınıfı için ÜD ve KD değerleri sırasıyla yaklaşık \%88 ve \%83 elde edilmiştir.

DVM ile elde edilen sonuç incelendiğinde; üretici doğruluğunda bina ve orman sınıfının genel doğruluk oranının düşük olduğu, kullanıcı doğruluğunda ise bina ve asfalt yol sinıflarının doğruluğunun düşük olduğu gözlenmiştir. Fındık sınıfı için ÜD ve KD değerleri sırasıyla yaklaşık \%94 ve \%87 elde edilmiştir. Fındık sınıfı ele alındığında en yüksek doğruluğu DVM yöntemi vermiştir, onu sırasıyla RO ve E-EYK yöntemleri vermiștir.

Sınıflandırma sonuçlarından elde edilen hata matrisleri incelendiğinde genel olarak tüm yöntemlerde benzer spektral özelliğe sahip olan sınıfların birbiriyle karıștığı görülmektedir. Yaz mevsiminin yaşandığı döneme ait Sentinel-2 görüntüsünde yeşil tonlarının ağırlıklı olduğu findıklık ve orman sınıfları birbirine yakın spektral değerlere sahip oldukları için en çok karışan sınıflar olmuşlardır. 

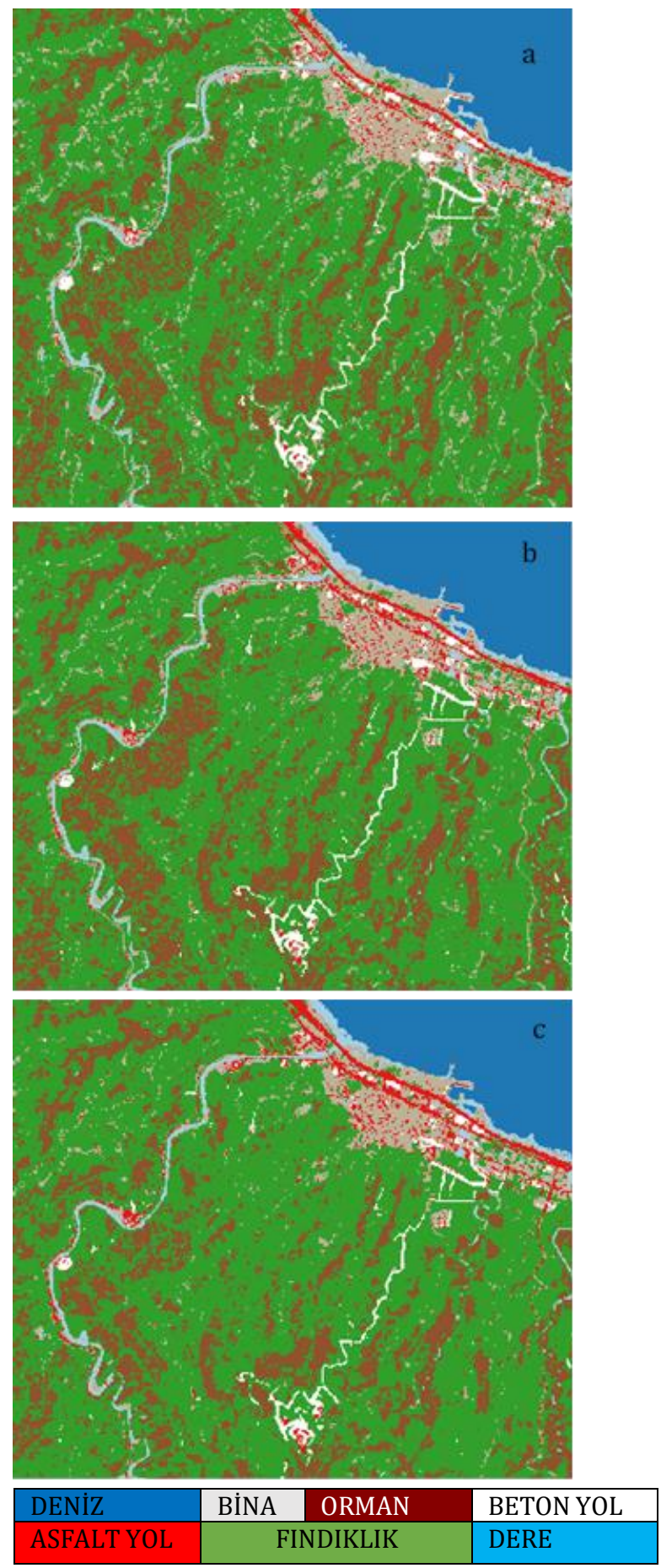

Şekil 5. a)RO, b) K-EYK ve c)DVM sınıflandırma sonucu üretilen arazi örtüsü sınıfları

Genbatu ve ark. (2020), benzer makine öğrenme algoritmalarını kullanarak yapmış olduğu çalışmada, Landsat-8 görüntüsü kullanarak arazi örtüsünü 7 farklı sınıfta incelemiștir. Sinıflandırma doğruluklarının karş̧laştırılması ile ilgili değerlendirme yapmışlardır. En yüksek genel doğruluğu yapay sinir ağları (\%97.2) vermiştir, onu R0 (\% 96.9), DVM (\% 96.2) ve K-EYK (\% 93.7) takip etmiştir. Arazi örtüsü türlerinin sınıflandırma doğruluklarına göre, boş arazi, sulak alan ve ormanlık alan, RO tarafından daha doğru bir şekilde sınıflandırdığını belirtmişlerdir. Bu çalış̧mada en yüksek toplam sınıflandırma doğruluğunu DVM yöntemi vermiştir, diğer çalışmalardan farklı olarak DVM yöntemini sırasıyla K-EYK ve RO yöntemleri vermiştir. Fındık sınıfı ele alındığında ise en yüksek ÜD değerleri sırasıyla DVM, RO ve K-EYK ile elde edilmiştir.

Tablo 3. Sınıflandırma sonuçlarına ait doğruluk değerleri

\begin{tabular}{|l|l|l|l|l|l|l|}
\hline \multirow{2}{*}{ Sinıflar } & \multicolumn{2}{|c|}{ RO } & \multicolumn{2}{c|}{ K-EYK } & \multicolumn{2}{c|}{ DVM } \\
\cline { 2 - 7 } & ÜD \% & KD \% & ÜD \% & KD \% & ÜD \% & KD \% \\
\hline Deniz & 99,96 & 99,88 & 99,98 & 99,90 & 99,97 & 99,86 \\
\hline Bina & 88,79 & 64,02 & 78,03 & 73,94 & 63,67 & 60,17 \\
\hline Orman & 64,56 & 85,92 & 73,55 & 81,45 & 78,43 & 93,20 \\
\hline Fındıklık & 89,15 & 78,21 & 87,68 & 83,29 & 93,73 & 87,19 \\
\hline Asfalt Yol & 84,30 & 77,09 & 96,49 & 60,93 & 94,98 & 56,93 \\
\hline Beton Yol & 72,51 & 97,69 & 77,42 & 99,27 & 85,10 & 90,92 \\
\hline Dere & 71,37 & 60,30 & 90,65 & 84,22 & 89,65 & 67,28 \\
\hline $\begin{array}{l}\text { Genel } \\
\text { doğruluk }\end{array}$ & 85,3870 & \multicolumn{7}{|c|}{87,5398} & 91,0948 \\
\hline \multicolumn{1}{|c|}{ Kappa } & 0,8089 & 0,8190 & \multicolumn{5}{c}{0,8696} \\
\hline
\end{tabular}

\section{SONUC}

Bu çalışmada ekonomik değere sahip olan fındık bahçelerinin yüksek doğrulukla belirlenmesi amaçlanmıștır. Uygulamada Beşikdüzü ilçesine ait Temmuz 2019 tarihli Sentinel-2 uydu görüntüsü kullanılmış ve 7 farklı ürün sınıfı belirlenerek açık kaynak kodlu ücretsiz QGIS yazılımı ile sınıflandırılmıştır. Çalışmada üç görüntü sınıflandırma algoritması Rasgele Orman, K En Yakın Komşu ve Destek Vektör Makineleri uygulanarak sınıflandırılmıştır ve karşılaştırılmıştır. Doğruluk analizi için k-katlamalı çapraz doğrulama yöntemi kullanılmış eğitim ve test verileri için ayrı ayrı 778 piksel seçilmiștir. Eğitim ve test verileri her seferinde değiștirilmiş ve ortalama değer alınarak model oluşturulmuştur. Tüm sınıflandırma sonuçları ele alındığında genel doğruluk oranları \%85 üzeri yüksek değerler almıştır. Üç farklı makine öğrenme algoritması arasında Rasgele Orman yöntemi, en düşük genel doğruluğa, DVM ise en yüksek genel doğruluk değerini sağlamıştır.

Üç algoritma için tüm sınıflar incelendiğinde; fındıklık sınıfının tespitinde hem üretici hem de kullanıcı doğruluğu en yüksek değerler DVM yöntemi ile sağlanmıștır. RO ve E-EYK yöntemleri birbirine yakın üretici doğruluğu sağlarken E-EYK daha yüksek kullanıcı doğruluğu vermiştir. E-EYK tek parametre kullanması açısından kolaylık sağlamaktadır ancak $\mathrm{k}$ değeri uygulamaya göre değişkenlik gösterebilmekte ve modelin kararsızlığına sebep olabilmektedir. DVM yöntemi en iyi sonucu vermesinin sebebi verilerin doğrusal olarak ayrılamadığı orman ve fındık alanlarının daha yüksek boyutlu bir özellik uzayına yansıtılmış olmasından kaynaklanmaktadır.

Bina ve asfalt yol ile fındıklık ve orman ürünleri birbirine en fazla karışan sınıflar olmuştur. Bu durum uydu görüntüsü çözünürlügünün çok yüksek 
olmamasından kaynaklı olduğuna yorumlanabilir. Bir sonraki çalışmada farklı zamanlarda alınan uydu görüntüleri değerlendirilerek fındık ağacının hangi evresinde daha iyi belirlenebileceğinin araştırılması planlanmıştır.

R0, K-EYK ve DVM makine algoritmaları ile Sentinel-2 görüntüsünün iyi bir sınıflandırma performansının elde edilebileceği gösterilmiştir.

\section{KAYNAKÇA}

Abdikan S., Bilgin G., Sanli F.B., Uslu E., Ustuner M. (2015) - Enhancing land use classification with fusing dual-polarized TerraSAR-X and multispectral RapidEye data. Journal of Applied Remote Sensing, 9: 096054-096054.

Adam, E., Mutanga, O., Odindi, J, Abdel-Rahman, E.M. (2014). Land-Use/Cover Classification İ A Heterogeneous Coastal Landscape Using Rapideye İmagery: Evaluating The Performance Of Random Forest And Support Vector Machines Classifiers. Int. J. Remote Sens. 2014, 35, 3440-3458.

Akar, Ö., Güngör, O., (2013). Eş Dizimlilik Matrisi Ve Rastgele Orman Sınıflandırıcısı İle Çay Ve Fındık Alanlarının Sınıflandırılması, Türkiye Ulusal Fotogrametri ve Uzaktan Algılama Birliği VII. Teknik Sempozyumu (TUFUAB'2013), 23-25 Mayıs 2013, KTÜ, Trabzon.

Akbulut, Y., Sengur, A, Guo, Y., Smarandache, F. (2017). NS-k-NN: Neutrosophic Set-Based kNearest classifier. Symmetry 2017, 9, 179

Breiman, L. (2001). Random forests,machine learning, 2001 Kluwer Academic Publishers, 45(1), 5-32.

Comert, R., Matcl, D.K., Avdan U. (2019). Object Based Burned Area Mapping with Random Forest Algorithm, International Journal of Engineering and Geosciences (IJEG), 4 (2), 078-087

Drusch, M., Del Bello, U., Carlier, S., Colin, O., Fernandez, V., Gascon, F., Hoersch, B., Isola, C., Laberinti, P. ve Martimort, P. (2012). Sentinel2: ESA's Optical High-Resolution Mission for GMES Operational Services, Remote Sens. Environ.,no. 120, p. 25-36.

Duda, R., Hart, P. (1973). Pattern Classification and Scene Analysis; John Wiley \& Sons: New York, NY, USA, 1973.

Franco-Lopez, H., Ek, A.R., Bauer, M.E. (2001). Estimation and mapping of forest stand density, volume and cover type using the k-Nearest
Neighbors method. Remote

Sens. Environ. 2001, 77, 251-274.

Genbatu G., Zhongjie S., Yuanjun Z., Xiaohui Y., Yuguang H. (2020). Land use/cover classification in an arid desert-oasis mosaic landscape of China using remote sensed imagery: Performance assessment of four machine learning algorithms, Conservation Volume, June 2020, e00971

Ghosh, A., Joshi, P.K. A. (2014). Comparison of Selected Classification Algorithms For Mapping Bamboo Patches İn Lower Gangetic Plains Using Very High Resolution Worldview 2 İmagery. Int. J. Appl. Earth Obs. Geoinf. 2014, 26, 298-311.

Gupta, N. and Bhadauria, H.S, (2014). Object Based Information Extraction from High Resolution Satellite Imagery using eCognition, International Journal of Computer sciences Issues, Vol. 11, 3, No. 2, 139-144.

He, H., Garcia, E.A. (2009). Learning from imbalanced data. IEEE Trans. Knowl. Data Eng. 2009;21:1263-1284.

Heydari, S.S., Mountrakis, G. (2018). Effect of classifier selection, reference sample size, reference class distribution and scene heterogeneity in per-pixel classification accuracy using 26 Landsat sites. Remote Sens. Environ. 2018, 204, 648-658.

Karakus, P., Karabork, H., Kaya, S., (2017). A Comparison Of The Classification Accuracies In Determining The Land Cover Of Kadirli Region Of Turkey By Using The Pixel Based And Object Based Classification Algorithms, International Journal of Engineering and Geosciences (IJEG), 2(2), 52-60.

Khatami, R., Mountrakis, G., Stehman, S.V. (2016). A Meta-Analysis Of Remote Sensing Research On Supervised Pixel-Based Land Cover İmage Classification Processes: General Guidelines For Practitioners And Future Research. Remote Sens. Environ. 2016, 177, 89-100.

Kohavi, R. (1995). A study of cross-validation and bootstrap for accuracy estimation and model selection. Ijcai 14(2), 1137-1145.

Malenovský, Z., Rott, H., Cihlar, J., Schaepman, E. M, García-Santos, G., Fernandes, R. and Berger, M. (2012). Sentinels for science: Potential of Sentinel-1, -2 and -3 missions for scientific observations of ocean, cryosphere, and land, Remote Sens. Environ., no. 120, p. 91-101.

Noi P. T., Kappas M., (2018). Comparison of Random Forest, k-Nearest Neighbor,and Support Vector 
Machine Classifiers for LandCover Classification Using Sentinel-2 Imagery, Sensors 2018, 18(1), 18.

Olofsson P., Foody G.M., Herold M., Stehman S.V., Woodcock C.E., Wulder M.A., (2014). Good practices for estimating area and assessing accuracy of land change Remote Sensing of Environment, 148, 42 - 57

Qian, Y., Zhou, W., Yan, J., Li, W., Han, L. (2015). Comparing machine learning classifiers for object-based land cover classification using very high resolution imagery. Remote Sens. 2015, 7, 153-168.

Reis S., Taşdemir K., (2010). Fındık Alanlarının Kendini Örgütleyen Eşlemlerle (Self Organizing Maps) Belirlenmesi, III. Uzaktan Algılama ve Coğrafi Bilgi Sistemleri Sempozyumu, 11 - 13 Ekim 2010, Gebze - KOCAELI.

Rwanga, S.S., Ndambuki J.M. (2017). Accuracy Assessment of Land Use/Land Cover Classification Using Remote Sensing and GIS. International Journal of Geosciences, 2017, 8, 611-622.

Sener M., Altıntas B., Kurc H.C. (2013). Planning and Controlling of Hazelnut Production Areas with the Remote Sensing Techniques KSU J. Nat. Sci., 16(1), 2013

Sevgen S.C. (2019). Airborne Lidar Data Classification In Complex Urban Area Using Random Forest: A Case Study of Bergama, Turkey, International Journal of Engineering and Geosciences (IJEG), 4 (1), 045-051.

Toosi, N. B., Soffianian, A. R., Fakheran, S., Pourmanafi, S., Ginzler, C., \& Waser, L. T. (2019). Comparing different classification algorithms for monitoring mangrove cover changes in southern Iran. Global Ecology and Conservation, e00662.

Url-1: http://www.ftg.org.tr/tr/turk-findigiturkiyede-findik.html erişim tarihi: 04.09.2019

Url-2: http://www.besikduzu.bel.tr /besikduzu erișim tarihi: 04.09.2019

Url-3: https://scihub.copernicus.eu/dhus/\#/home erişim tarihi: 04.09.2019

Url-4: https://www.harrisgeospatial.com /docs/backgroundsvmgeneral.html erişim tarihi: 29.02.2020

Ünal, E., Aydoğdu, M., Ceylan, N., Sezer, A., Özenç, N., Duyar, Ö. (2010). Giresun İlinde Findık Alanlarının Uzaktan Algılama İle Tespit Edilmesinde Arazi Topografyasının Etkisinin İncelenmesi Ve Alternatif Tarım Ürünlerine Uygunluğunun Belirlenmesi, Tarla Bitkileri Merkez Araștırma Enstitüsü Dergisi, 2010, 19 $(1-2): 1-10$

Üstüner, M. , Balık Șanlı, F., Abdikan, S., Esetlili, M.T., Kurucu. (2014). Kirmızı-Kenar Ve Yakın Kızılötesi Bantlarının Ürün Deseni Sınıflandırma Doğruluğuna Olan Etkisinin Araştırılması: Rapideye Örneği. 5. Uzaktan Algilama-Cbs Sempozyumu (Uzal-Cbs 2014), 14-17 Ekim 2014, İstanbul.

Üstüner, M. , Balık Şanlı, F., (2019). Çok Zamanlı Polarimetrik SAR Verileri İle Tarımsal Ürünlerin Sinıflandırılması, Jeodezi Ve Jeoinformasyon Dergisi, 2019, 1-10.

Wei, C., Huang, J., Mansaray, L. R., Li, Z., Liu, W., Han, J. (2017). Estimation and mapping of winter oilseed rape LAI from high spatial resolution satellite data based on a hybrid method. Remote Sens. 2017, 9, 488. 